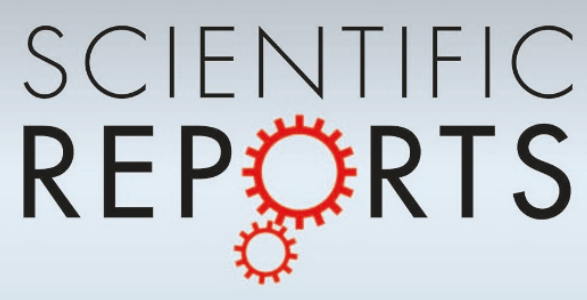

OPEN

SUBJECT AREAS:

PROTEOMIC ANALYSIS

IMMUNOPRECIPITATION

PROTEIN-PROTEIN INTERACTION

NETWORKS

Received

11 September 2013

Accepted

26 February 2014

Published

14 March 2014

Correspondence and requests for materials should be addressed to Y.K. (biolab@snu.ac.

$\mathrm{kr}$ )

* These authors contributed equally to this work.

\section{Interactome analysis of AMP-activated protein kinase (AMPK)- $\alpha 1$ and $-\beta 1$ in INS-1 pancreatic beta-cells by affinity purification-mass spectrometry}

\author{
Sungyoon Moon ${ }^{1,2 *}$, Dohyun Han ${ }^{1,2,4 *}$, Yikwon Kim ${ }^{1,2}$, Jonghwa Jin ${ }^{1,2}$, Won-Kyung Ho $\mathrm{H}^{1,3}$ \\ \& Youngsoo $\mathrm{Kim}^{1,2,4}$
}

\begin{abstract}
'Department of Biomedical Sciences, Seoul National University College of Medicine, 28 Yongon-Dong, Seoul $110-799$ Korea, ${ }^{2}$ Department of Biomedical Engineering, Seoul National University College of Medicine, 28 Yongon-Dong, Seoul 11 0-799 Korea, ${ }^{3}$ Department of Physilogy, Seoul National University College of Medicine, 28 Yongon-Dong, Seoul $110-799$ Korea, ${ }^{4}$ Institute of Medical \& Biological Engineering, Medical Research Center, Seoul National University College of Medicine, 28 Yongon-Dong, Seoul $110-799$ Korea.
\end{abstract}

The heterotrimeric enzyme AMP-activated protein kinase (AMPK) is a major metabolic factor that regulates the homeostasis of cellular energy. In particular, AMPK mediates the insulin resistance that is associated with type 2 diabetes. Generally, cellular processes require tight regulation of protein kinases, which is effected through their formation of complex with other proteins and substrates. Despite their critical function in regulation and pathogenesis, there are limited data on the interaction of protein kinases. To identify proteins that interact with AMPK, we performed large-scale affinity purification (AP)-mass spectrometry (MS) of the AMPK- $\alpha 1$ and $-\beta 1$ subunits. Through a comprehensive analysis, using a combination of immunoprecipitaion and ion trap mass spectrometry, we identified 381 unique proteins in the AMPK $\alpha / \beta$ interactomes: 325 partners of AMPK- $\alpha 1$ and 243 for AMPK- $\beta 1$. Further, we identified 196 novel protein-protein interactions with AMPK- $\alpha 1$ and AMPK- $\beta 1$. Notably, in our bioinformatics analysis, the novel interaction partners mediated functions that are related to the regulation of actin organization. Specifically, several such proteins were linked to pancreatic beta-cell functions, including glucose-stimulated insulin secretion, beta-cell development, beta-cell differentiation, and cell-cell communication.

M ammalian adenosine monophosphate-activated protein kinase (AMPK) is a serine-threonine kinase that regulates energy homeostasis at the cellular and whole-body levels ${ }^{1-3}$. AMPK is a heterotrimer that comprises a catalytic $\alpha$ subunit, a scaffolding $\beta$ subunit, and a regulatory $\gamma$ subunit ${ }^{1,2}$. Orthologs $(\alpha 1, \alpha 2$, $\beta 1, \beta 2, \gamma 1, \gamma 2, \gamma 3)$ of AMPK subunits are found in all eukaryotic species and expressed in many tissues ${ }^{2}$, suggesting that the structure and regulation of AMPK are evolutionarily conserved ${ }^{4}$.

AMPK is activated by nutrient deficiency and cellular stresses, such as glucose deprivation and hypoxia, which initiate metabolic adaptation programs to preserve cellular energy and maintain viability in various tissues, including skeletal muscle, cardiac muscle, adipose tissue, pancreas, and liver ${ }^{2,3,5,6}$. In general, AMPK activity is regulated through allosteric activation by adenine nucleotides, phosphorylation via upstream kinases ${ }^{7,8}$, and inhibition of dephosphorylation by protein phosphatases?

After activation, AMPK phosphorylates many substrates that regulate metabolism ${ }^{10}$, signaling ${ }^{11}$, gene expression $^{12}$, and tissue-specific glucose and lipid homeostasis ${ }^{13}$. Based on these functions, AMPK is linked to various metabolic diseases, such as type 2 diabetes, obesity, hormonal disorders, cardiovascular disease, and cancer, ${ }^{2,7}$. Drugs that activate AMPK, such as metformin and thiazolidinediones, are mainstays in the treatment of type 2 diabetes, underscoring the importance of targeting the AMPK pathway to control metabolic disorders ${ }^{2,3,5-8}$.

Recent evidence suggests that AMPK mediates many functions in pancreatic beta-cells, including glucosestimulated insulin secretion (GSIS) ${ }^{14}$, proliferation ${ }^{15}$, and survival ${ }^{16}$. Because pancreatic beta-cells have distinct processes with regard to glucose metabolism and depend heavily on glucose and energy-sensing for their function and survival, the functions of AMPK must be examined in beta-cells, which have been described in liver and 
skeletal muscle. Further, recent findings have demonstrated that AMPK is a positive and negative regulator of insulin secretion ${ }^{14}$. Based on this duality, considerable effort is under way to determine the functions of AMPK in pancreatic beta-cells. Yet, how AMPK regulates beta-cell function remains unknown ${ }^{14}$.

Protein-protein interactions are crucial in all cellular processes ${ }^{17,18}$. As expected, interactions between AMPK and proteins in its downstream pathway are important for most of its functions ${ }^{19}$. Despite the significance of AMPK in beta-cell functions, the interactions between AMPK and other proteins in beta-cells have not been studied extensively. Thus, identifying target molecules that interact with AMPK is critical to understand the functions that are mediated by AMPK. Also, such information can increase our understanding of disease mechanisms and provide the basis for more specific therapies.

Recent protein interaction studies that are based on mass spectrometry-based proteomics have examined this issue in a systematic and relatively unbiased manner ${ }^{17,18}$, based on technological advances in mass spectrometry. Specifically, affinity purification, followed by mass spectrometry analysis (AP-MS), has become the preferred method of characterizing protein interactions ${ }^{20,21}$.

We performed an extensive study of proteins that interact with AMPK- $\alpha 1$ and $-\beta 1$, which are more highly expressed in pancreatic beta-cells than AMPK- $\alpha 2$ and $\beta 2^{15,22}$. To identify proteins that interact with these subunits, we performed an affinity purification and spectrometric analysis (AP-MS) using a combination of pulldown assay and direct immunoprecipitation of AMPK- $\alpha 1$ and - $\beta 1$ in INS1 beta-cells. After a significance analysis using the SAINT program, our interactome comprised 325 and 243 proteins that interacted with AMPK- $\alpha 1$ and $-\beta 1$, respectively, 196 (51\%) of which were novel partners.

Next, we performed a functional classification of our interactome. Several proteins that regulated actin organization were linked to pancreatic beta-cell functions including, GSIS, beta-cell development, beta-cell differentiation, and cell-cell communication. We also validated those interacting proteins that regulated actin cytoskeletal organization. Our interactome data constitute a substantial amount of new information on AMPK-specific interactions.

\section{Results}

Overall scheme for profiling of AMPK- $\alpha 1$ and $-\beta 1$ interactomes. To identify the interactomes of AMPK- $\alpha 1$ and AMPK- $\beta 1$ in pancreatic beta-cells, we performed a comprehensive AP-MS analysis, combining pulldown experiments using tagged recombinant baits and direct immunoprecipitation (direct IP) of endogenous target proteins (Figure 1).

Initially, we planned to overexpress 6-myc epitope-tagged AMPK$\alpha 1$ and AMPK- $\beta 1$ by transfection in INS- 1 cells. However, we could not obtain a sufficient amount of myc-tagged proteins to perform AP-MS, due to the low transfection efficiency of INS-1 cells (Figure 2A). Alternatively, we overexpressed N-terminally 6-myctagged rat AMPK- $\alpha 1$ and AMPK- $\beta 1$ in HEK293T cells and immobilized them to Dynabeads (Figure 1A, Bait production). Briefly, to express the recombinant proteins, full-length rat AMPK- $\alpha 1$ and $-\beta 1$ cDNA was subcloned into modified pcDNA3.1 and transfected into HEK293T cells by PEI method ${ }^{23,24}$.

For the pulldown approach (Figure 1), we used magnetic beads (Dynabeads) as the IP material. Recombinant AMPK subunits from $1 \mathrm{mg}$ of transfected HEK293T cells were immobilized using antimyc-conjugated Dynabeads. To prevent any bias from immobilization of the antibody, anti-myc-conjugated Dynabeads that were incubated with mock-transfected HEK293T lysates were used as bait in the negative control experiment (Figure 1A). To remove nonspecific lysate products, INS-1 lysates were precleared with the same material as in the IP (Figure 1B) ${ }^{25}$. Subsequently, the immobilized 6-myc-tagged AMPK- $\alpha 1$ and - $\beta 1$ were used as bait in pulldown assays with $1 \mathrm{mg}$ of INS-1 lysate (Figure 1C). Eluted samples from the bait production (Figure 1A) were analyzed by LC-MS/MS to confirm the coelution of false-positive interactors and to examine homologous interactions in HEK293T cells (Figure 1D, HEK293T control experiments).

The proteins that coprecipitated with the myc-tagged baits were separated on a 1-DE $10 \%$ bis-tris SDS-PAGE gel and subjected to ingel trypsin digestion. Finally, the peptide mixtures were desalted using $\mathrm{C}_{18}$-Stagetips ${ }^{26}$ and analyzed on an LTQ Velos linear ion trap LC-MS/MS system (Figure 1E). Two biological replicates and 3 technical replicates were analyzed.

Further, to increase the coverage and enhance the reliability of the AMPK interactome, direct IP was performed without overexpression of the target baits (Figure 1). Briefly, native protein complexes were isolated directly using antibodies against AMPK- $\alpha 1$ and AMPK- $\beta 1$ from $10 \mathrm{mg}$ of INS-1 cell lysate. Anti-IgG served as the negative control. The proteins that coprecipitated with the endogenous baits were eluted with acid buffer and subjected to filter-aided sample preparation (FASP) ${ }^{27,28}$. Finally, peptide desalting and MS analysis were performed as described above (Figure 1E).

Consequently, we generated 4 datasets of the AMPK interactome (AMPK- $\alpha 1$ pulldown, AMPK- $\alpha 1$ direct IP, AMPK- $\beta 1$ pulldown, and AMPK- $\beta 1$ direct IP); all experiments were performed with biological duplicates and technical triplicates.

Expression, immobilization, and pulldown were verified by western blot (Figure 2). Overexpression of myc-tagged AMPK- $\alpha 1$ and $-\beta 1$ in HEK293T cells was confirmed by western blot with anti-myc, whereas we could not detect any myc-tagged proteins in INS-1 cells (Figure $2 \mathrm{~A}$ ). Western blot with AMPK- $\alpha 1$ and $-\beta 1$ antibodies was also performed to verify the immobilization and coelution of AMPK$\alpha 1$ and $-\beta 1$ in the elution fractions of each IP step. AMPK- $\alpha 1$ and $-\beta 1$ were detected in the elution fractions of the target baits but not the mock control lane in the pulldown (Figure 2B), indicating that our approach reliably identified interactors of the targets of interest.

Finally, aliquots of the pulldown and immunoprecipitation fractions were loaded onto an SDS-PAGE gel and stained with silver nitrate. Bands that appeared to correspond to AMPK- $\alpha 1$ and $-\beta 1$ and their interacting partners were observed in the target bait IP (Supplementary Figures 2A \& 2B).

Identification of novel AMPK- $\alpha 1$ - and - $\beta 1$ - interacting proteins. For the pulldown approach, recombinant rat AMPK subunits were overexpressed as baits in HEK293T cells, suggesting that some of the identified interactors originated from human cells. Thus, the proteins that interact with AMPK subunits in INS-1 cells must be classified with regard to species. To separate the interacting proteins that were derived solely from HEK293T cells, MS/MS spectra were searched on the Sorcerer-SEQUEST platform ${ }^{29}$ using a target-decoy strategy against a concatenated database that contained the human IPI database (version 3.87, 91,464 entries), rat IPI database (version 3.87, 39,925 entries), and their reverse-complements. Conversely, for the direct IP approach, MS/MS spectra were searched only in the Sorcerer-SEQUEST platform ${ }^{29}$ using a target-decoy strategy against a concatenated database of the rat IPI database. All search results were validated and filtered using Scaffold 4 to establish AP-MS datasets at an FDR $<1.0 \%$ (Figure 3A).

Raw data on 36 LC-MS/MS spectra were collected, resulting in 20,421 unique spectra; 18,377 unique peptides, corresponding to 1233 unique proteins, were identified at an FDR of $1 \%$ (Supplementary Table S1). In experiments in which AMPK- $\alpha 1$ was used as bait, an average of 286 and 443 unique proteins were identified in the 2 biological replicates of the pulldown and direct IP approaches, respectively. With AMPK- $\beta 1$ as bait, an average of 179 and 447 unique proteins were identified in the 2 biological replicates of the pulldown and direct IP approaches, respectively (Table 1). 

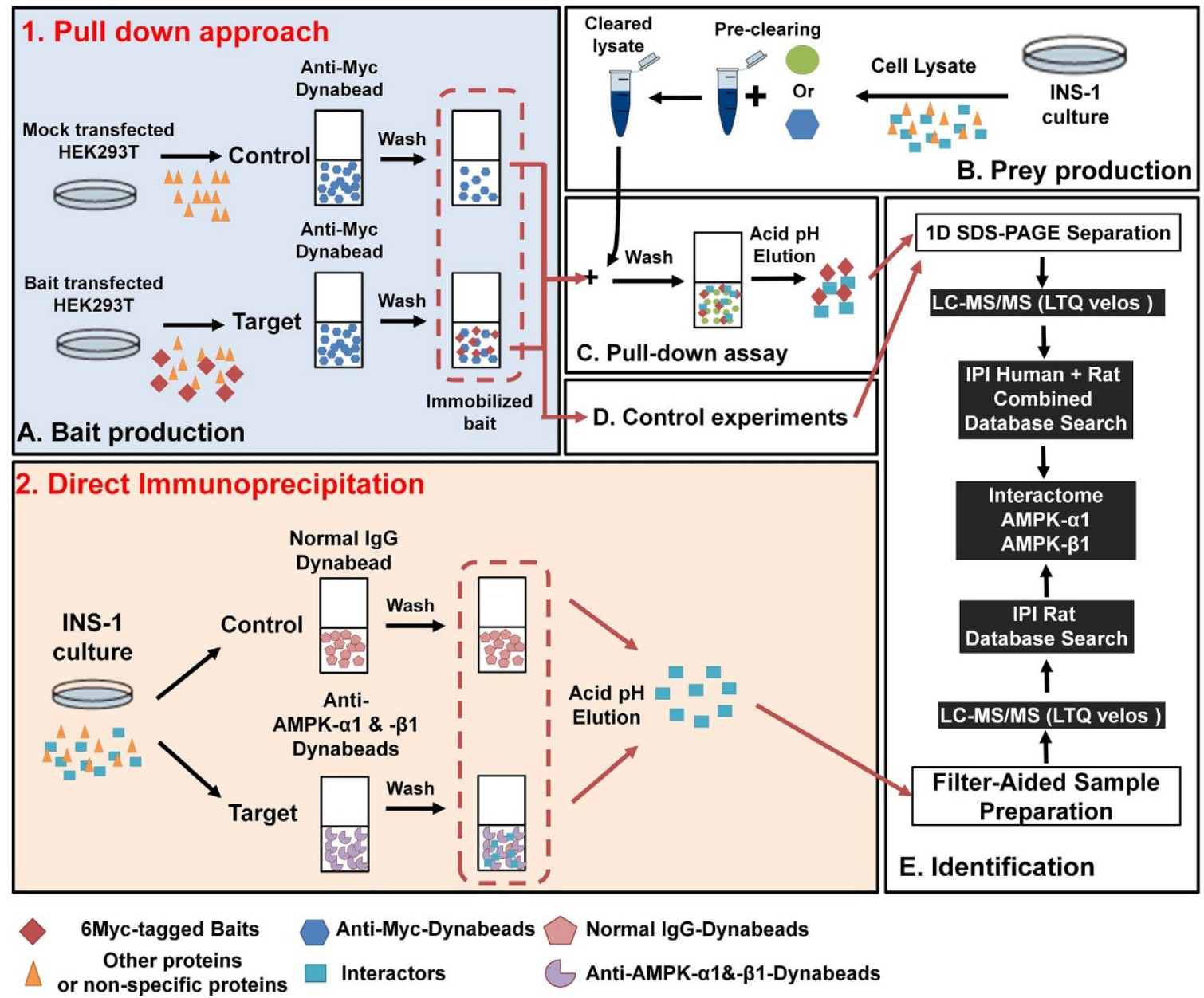

Figure $1 \mid$ Experimental scheme to examine interactomes of AMPK subunits. The AP-MS procedure comprised 5 steps in series: (A). bait production, (B). prey production, (C). pulldown assay, (D). control experiments, and (E). identification. To compare protein interactions, we performed pulldown and direct immunoprecipitation (IP). In the pulldown approach, recombinant myc-AMPK was purified from HEK293T lysates using anti-mycconjugated Dynabead baits and linked covalently to matrices for incubation with INS-1 cell lysate (B). The proteins that bind to Myc-tagged AMPK proteins were immunoprecipitated and separated on a 1-DE 10\% Bis-Tris gel and subjected to in-gel trypsin digestion (C). The digested samples were desalted using $\mathrm{C}_{18}$ stage tips. After sample clean-up, the peptides were analyzed by LC-MS/MS. A database search was performed using the Sorcerer platform against a concatenated target-decoy database that contained the rat IPI and human IPI databases and their reverse-complements (E). In the direct IP, endogenous AMPK subunits were immunoprecipitated in INS-1 cells. Interacting proteins between the control and target AMPK groups were analyzed using Scaffold 4 .

Bait recovery of the pulldown approach yielded an average of 294 and 299 spectral counts with $33 \%$ and $57 \%$ coverage for tagged AMPK- $\alpha 1$ and $-\beta 1$, respectively. In addition, bait recovery of the direct IP approach generated an average of 42 and 20 spectral counts with $17 \%$ and $11 \%$ coverage for tagged AMPK- $\alpha 1$ and $-\beta 1$, respectively (Supplementary Table S1). Because AMPK- $\alpha 1$ and - $\beta 1$ form a complex in cells, we examined whether AMPK subunits were detected in our datasets to determine the reliability of our proteomic approaches. As shown in Supplementary Figure 3 and Supplementary Table S1, nearly all AMPK subunits that were expressed in pancreatic beta-cells, such as AMPK- $\alpha 1$, AMPK- $\alpha 2$, AMPK- $\beta 1$, and AMPK- $\gamma 1$, were identified with the target baits, whereas the control baits did not contain the spectral counts of AMPK subunits. These results indicate that our AP-MS approaches are reliable.

To remove nonspecific interactors, we performed SAINT analysis ${ }^{30}$, as shown in Figure 3A. First, in each experiment, unweighted spectral counts of proteins that were identified in the samples that corresponded to the control and baits were exported from Scaffold 4. Then, to include only high-confidence proteins, proteins had to have been identified in all 3 technical replicates with a protein probability score $\geq 0.95$ to be input into the SAINT analysis (Supplementary
Table S2). In 4 individual experiments per target bait, identifications were accepted for proteins that appeared in at least 2 experiments with an average individual probability for SAINT analysis (AvgP SAINT) $\geq 0.50$. In addition, single-protein hits were considered positive at AvgP SAINT $\geq 0.90$ (Supplementary Table S3).

Finally, for the pulldown approach, the amino acid sequences of the filtered proteins were examined with regard to species using the protein grouping algorithm in Scaffold 4 to sort INS-1-specific interactors. In Scaffold 4, proteins that are identified with the same sequence of a peptide (ie, the sharing peptide) are represented as protein groups. Because we used a concatenated human and rat database in the pulldown approach, we could verify whether the identified proteins were human or rat. For example, if a protein group comprises only rat proteins, it clearly matches rat proteinsnot its human orthologous counterpart. However, if a protein group contains a mixture of human and rat proteins, we can conclude that it was derived from HEK293T or INS-1 cells.

Thus, the proteins that were identified in the pulldown approach were classified into 3 groups: Rat_only, Rat_Human_Concurrently, and Human_only. To avoid missed interactions and recover homologous interactions in the pulldown approach, only proteins in 


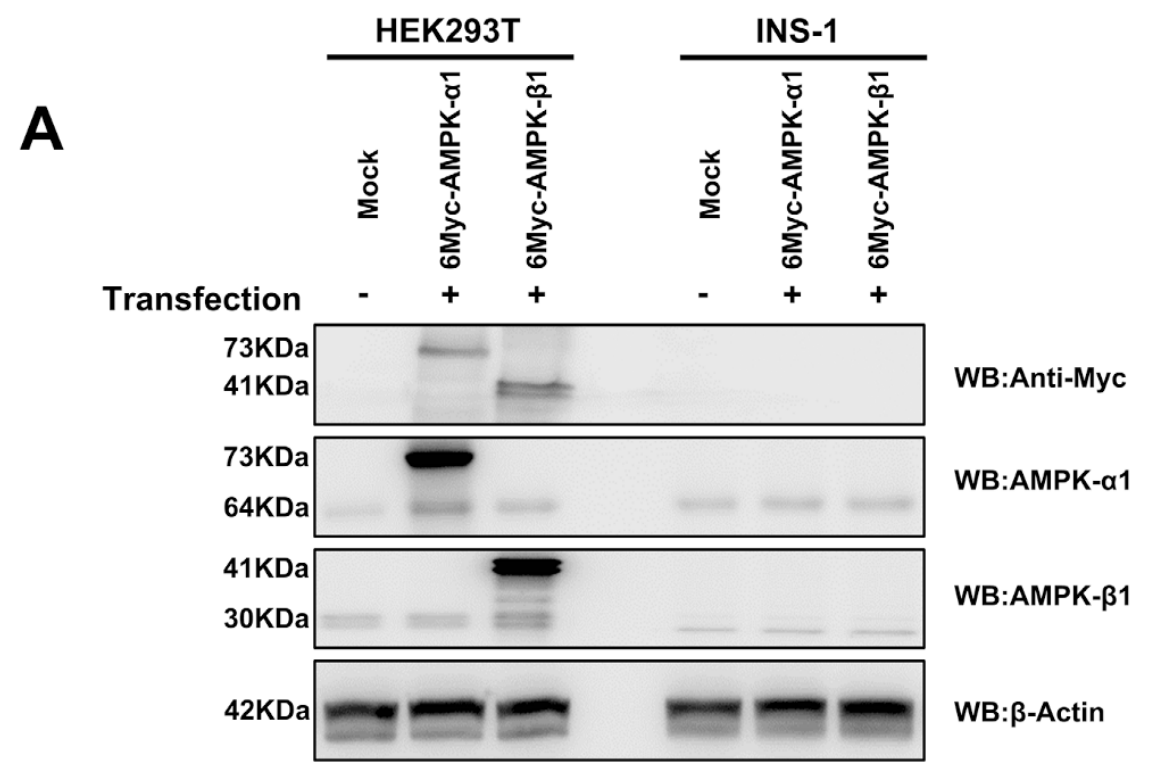

B



Figure $2 \mid$ Purification of AMPK subunits in control versus target myc-AMPK IP groups. (A) Lysates from HEK293T cells and INS-1 cells expressing pcDNA3.1 or Myc-AMPK $\alpha 1 / \beta 1$ were immunoblotted with anti-c-Myc. (B) Lysate from HEK293T cells expressing pcDNA3.1 or Myc-AMPK $\alpha 1 / \beta 1$ was incubated with anti-c-Myc-conjugated Dynabeads and covalently coupled to matrices for incubation with INS-1 cell lysate. Bound proteins were eluted and subjected to western blot with anti-AMPK- $\alpha 1$ and $-\beta 1$.

the Rat_Human_Concurrently and Human_only groups that had at least $99 \%$ sequence identity between the rat and human homologs were included in the final list by BLAST analysis (Figure 3B). In total, 325 AMPK- $\alpha 1$ and 243 AMPK- $\beta 1$ interactors were identified in this study and classified as the "INS-1 specific group". In addition, 97 AMPK- $\alpha 1$ - and 92 AMPK- $\beta 1$-binding partners in the HEK293T control experiments (the human species group, Fig. 1D) are shown in Supplementary Table S4. For further analysis, the HEK293T control experiments were processed under the same conditions as with the INS-1-specific group.

Functional classification of AMPK-specific interactors. To determine the functions of proteins that interact with AMPK subunits in INS- 1 cells, the AMPK- $\alpha 1$ and $-\beta 1$ binding partners were grouped by Gene Ontology (GO) term using the DAVID bioinformatics resource tool into biological process, cellular compartment, and molecular function ${ }^{31}$. To identify the GO categories that were overrepresented in proteins in INS-1 cells, the INS-1-specific groups and human species group were subjected individually to GO analysis (Figure 4).

By GO analysis, AMPK- $\alpha 1$ - and - $\beta 1$-interacting proteins were enriched globally in AMPK-mediated processes with similar patterns, regardless of species affiliation (Figures $4 \mathrm{~A}$ and $4 \mathrm{~B}$ ). For example, the commonly enriched categories in the 2 groups of the datasets were linked to major pathways that are associated with AMPK, such as metabolism $^{3,5}$, translation ${ }^{32}$, and biosynthesis. Also, most proteins were distributed broadly throughout the cytosol, mitochondria, nucleolus, and ribosome. AMPK- $\alpha 1-$ and $-\beta 1$-interacting proteins that mediate the organization and regulation of the actin cytoskeleton were significantly enriched in the INS-1-specific versus human species group (Figures $4 \mathrm{~A}$ and $4 \mathrm{~B}$ ). In addition, many proteins in the INS-1specific group were involved in transport, the cell cycle, and cytoskeletal protein binding. The similarity in patterns between AMPK- $\alpha 1$ and $-\beta 1$ interactors in the GO analysis might be attributed to the structural conformation of the heterotrimeric AMPK complex, which contains AMPK- $\alpha 1$ and $-\beta 1$. All information on the GO annotations is listed in Supplementary Table S5.

To examine the signaling pathways in our AMPK interactome, we analyzed our data using the KEGG pathway database (http://www. genome.jp/kegg/) and DAVID bioinformatics tool ${ }^{31}$. A total of 381 AMPK- $\alpha 1$ - and - $\beta 1$-interacting proteins in the INS-1-specific group fell into the following KEGG pathway categories: Ribosome, Spliceosome, Huntington disease, Parkinson disease, Adherens junction, and Regulation of actin cytoskeleton (Supplementary Table S6). Notably, KEGG pathway analysis of the human species groups demonstrated that only proteins in the INS-1-specific groups were significantly enriched with regard to regulation of the actin cytoskeleton (Supplementary Table S6).

Fifteen proteins regulated organization of the actin cytoskeleton, which is consistent with the GO analysis. In addition, based on a literature search ${ }^{33}$, Myl12b was linked to actin cytoskeletal organization. Consequently, 16 proteins that were associated with actin cytoskeletal organization were obtained, based on the functional classification (Table 2).

In pancreatic beta-cells, the actin cytoskeleton has significant functions in many processes, including GSIS, cell-cell adhesion, 




Figure $3 \mid$ Strategy of SAINT analysis for interactome. To remove nonspecific interactors, we used stringent filtering criteria and the SAINT algorithm. (A) Flowchart of data processing for AMPK interactome. MS datasets from the pulldown assay and direct IP were filtered sequentially with the filtering criteria. Further, SAINT, species affiliation, and BLAST analysis were performed consecutively to differentiate high-confidence interactors and nonspecific contaminants. (B) Identification of proteins that interact with AMPK- $\alpha 1$ and $-\beta 1$ subunits. The number of identified proteins is shown for each stage of the data processing. AMPK- $\alpha 1$ pulldown assay, AMPK- $\beta 1$ pulldown assay, AMPK- $\alpha 1$ direct IP, and AMPK- $\beta 1$ direct IP are labeled in blue, red, green, and orange, respectively.

and proliferation ${ }^{22,34,35}$. Although whether AMPK interacts directly with components in the actin cytoskeleton is unknown, recent studies have indicated that AMPK regulates its organization to mediate cell mobility and migration ${ }^{36-38}$. Based on the novelty of these results, we focused on the interactions of proteins that are associated with actin cytoskeletal organization.

Interaction of proteins related to actin cytoskeletal organization with AMPK. To examine the interactions between proteins that regulate actin cytoskeletal organization and AMPK, we generated a protein interaction network of 140 proteins from the KEGG pathway database using STRING 9.1 ${ }^{39}$ and Cytoscape ${ }^{40}$. The evidence-based global STRING-generated protein network ${ }^{39}$ showed high connectivity between actin cytoskeleton-regulating proteins (Figure 5A). However, the relationship between AMPK and actin cytoskeletal organization was not well defined in the protein interaction network. Thus, we added 28 direct interactions between 17 actin cytoskeleton-related proteins and AMPK- $\alpha 1 /-\beta 1$ to the protein interaction network (Figure 5A \& Table 2).

Of the interactions that were detected by AP-MS, the binding of Iqgap1, Gsn, and Vim to AMPK- $\alpha 1$ and $-\beta 1$ was confirmed by coimmunoprecipitation using 6-myc-tagged AMPK- $\alpha 1$ and $-\beta 1$. As shown in Figure 5B, IQGAP1 and gelsolin (Gsn) coimmunoprecipitated with both AMPK subunits. Vimentin (Vim) was used as the positive control, based on the robust interaction between vimentin and AMPK.

The interaction with Myh9, IQGAP1, Rhoa, and Rac1 was validated by direct coimmunoprecipitation in INS-1 cells (Figure 5C). The interaction between AMPK- $\alpha 1$ and $-\beta 1$ was tested as the positive control. In total, we validated the interactions of 6 proteins (Gsn, Iqgap1, Vim, Myh9, Rhoa, and Rac1) that were linked to regulation of the actin cytoskeleton, demonstrating that AMPK- $\alpha 1$ and $-\beta 1$ bind to the actin cytoskeleton and interact physically with regulators of the actin cytoskeleton organization.

\section{Discussion}

The aim of this study was to identify AMPK-interacting proteins in pancreatic beta-cells. For the AP-MS analysis, we first examined the expression of tagged baits in HEK293T cells, a cell type that has high transfection rates, because INS-1 beta-cells have low transfection efficiency of DNA vectors. Although we tried to exclude binding partners that arose solely from the HEK293T cells through a negative control experiment and species affiliation analysis with a combination database (human and rat) search, it is possible that false-positive interactors and overlooked interactions existed in our pulldown approach.

To verify the reliability of the species affiliation analysis in the pulldown approach, we performed several preliminary control experiments. In generating the tagged AMPK baits (Figure 1A), the proteins that were considered to have originated from HEK293T cells were analyzed by LC-MS/MS without incubation with INS-1 cell extracts (Figure 1D), whereas the baits was incubated with INS-1 cell extracts in the pulldown assay (Figures 1B \& 1C). These experiments indicated that that species affiliation analysis distinguished the origins of proteins in the pull-down of INS-1 cell extracts with myc-AMPK- $\alpha 1$ and - $\beta 1$ (Supplementary Figure 4A).

Further, BLAST analysis was performed to prevent missed interactions and increase the sensitivity in the pulldown assay. Only proteins with at least $99 \%$ sequence identity between the human and rat orthologs in the Rat_Human_Concurrently and Human_only groups were included in the final list. To ensure the specificity of the BLAST analysis, vimentin ( $98 \%$ sequence identity between human and rat), an interactor of AMPK- $\alpha$ and $-\beta^{21,41}$, was used as the positive control. Despite its sequence identity (98\%), we confirmed a homologous interaction between vimentin and AMPK subunits (Figure $5 \mathrm{~B}$ ), suggesting that the BLAST analysis could rescue a homologous interaction in the pulldown approach.

As shown in Supplementary Figure 4B, our BLAST analysis recovered approximately $50 \%$ of proteins that were identified as 


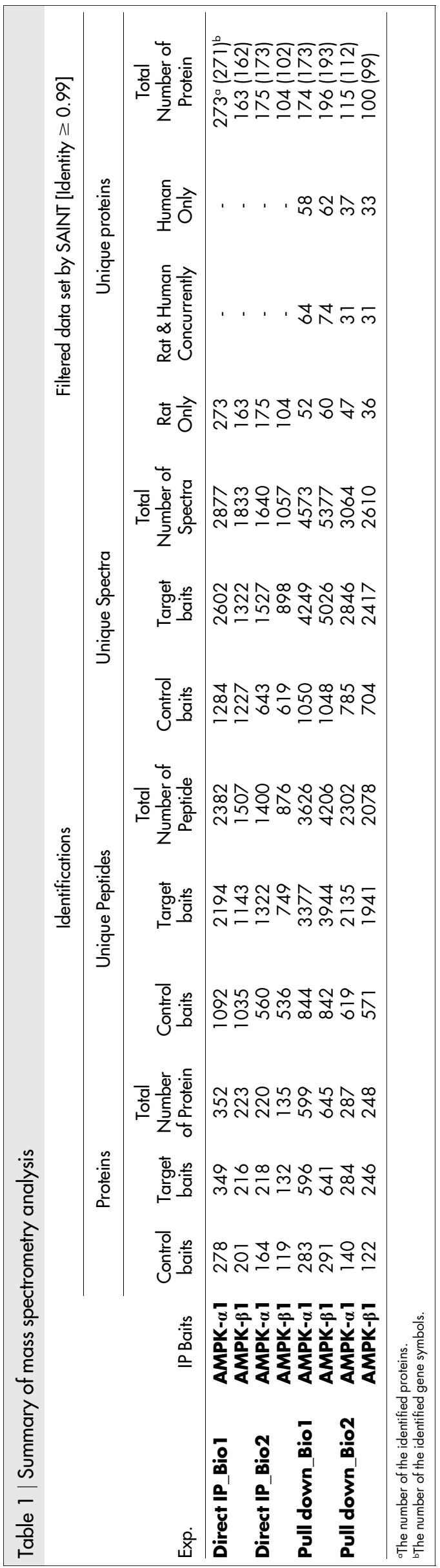

Human_only and Rat_human_concurrently after the filtration per the $99 \%$ sequence identity criterion. Moreover, the similar distribution of sequence identities in the HEK293T control experiments demonstrates that the BLAST analysis was not biased against the pulldown assay (Supplementary Figure 4B).

To overcome the limitations of the pulldown assay and increase coverage of the AMPK interactome with high confidence, direct IP was performed using antibodies against AMPK- $\alpha 1$ and $-\beta 1$ in INS- 1 cells without overexpression of baits. In addition, the pulldown and direct IP experiments were repeated independently with each bait and processed using the SAINT algorithm ${ }^{30}$. The SAINT statistical platform allowed us to assign confidence scores to interacting proteins from our AP-MS experiments. SAINT uses spectral counts of identified proteins to derive a probability score of a true interaction and discerns true interaction partners from background noise $\mathrm{e}^{30}$.

Thus, we used a stringent AP-MS strategy that was complemented by bioinformatics, SAINT analysis, and affinity purification-combining pulldown assay and direct immunoprecipitation-to draft the AMPK- $\alpha 1$ and $-\beta 1$ interactome in INS- 1 pancreatic beta-cells. Because we combined the Human and Rat IPI databases in the pulldown assay, the IPI accession numbers of the identified proteins were converted to gene names (symbols) and subjected to comparison analysis.

The Venn diagrams in Supplementary Figures 5A show the overlap in unique proteins between the pulldown assay and direct IP for AMPK- $\alpha 1$ and $-\beta 1$. These results demonstrate that our approaches provide complementary coverage and that their combination effects comprehensive coverage of the AMPK- $\alpha 1$ and $-\beta 1$ interactomes. Although the overlap between datasets was low due to biological and technical variations between the approaches and the use of low-resolution mass spectrometry ${ }^{42}, 201(62 \%)$ and $116(48 \%)$ proteins were identified in at least 2 of 4 biological replicates for AMPK$\alpha 1$ and $-\beta 1$, respectively. Notably, between the AMPK- $\alpha 1$ and AMPK- $\beta 1$ datasets that were merged from the approaches, there was $58 \%$ to $77 \%$ overlap (187 of 325 and 243 proteins in AMPK$\alpha 1$ and AMPK- $\beta 1$ each, respectively), which is better compared with the individual methods (Supplementary Figure 5B). Although the overlap between experiments was not high, the approaches enhanced coverage and identified distinct segments of the AMPK interactome.

We compared our AMPK- $\alpha 1$ and $-\beta 1$ interactome with existing data. Although several partners of AMPK- $\alpha 1$ and $-\beta 1$ have been reported $^{21,41,43}$, no global interactome analysis has focused on AMPK subunits. In particular, none of the well-characterized partners of these subunits have been identified in pancreatic beta-cells, based on mass spectrometry.

Large-scale proteomic data on AMPK interactors have been reported by Behrends et al. ${ }^{21}$, Pilot-Storch et al. ${ }^{43}$, and Varjosalo et $\mathrm{al}^{41}$ in human cell lines. The 614 proteins in these reports were compared directly with our AMPK- $\alpha 1$ and $-\beta 1$ interactors, based on gene name (symbol) (Supplementary Figure 6A). Of the 381 proteins in our list, there were 145 proteins with the same gene name in the 3 datasets. In addition, we compared our interactome with a public database $^{44}$. A total of 253 interactions for AMPK- $\alpha 1$ and $-\beta 1$ were obtained from the Protein Interaction Network Analysis (PINA) 2.0 database $\mathrm{e}^{44}, 41$ of which were common between our interactome and the database (Supplementary Figure 6B). Further, our data were compared with the results of the protein-protein interaction prediction by the PrePPI server ${ }^{45}$, which included 736 and 675 interactions of AMPK $-\alpha 1$ and $-\beta 1$ in human cells, respectively, 63 of which were found in our data (Supplementary Figure 6C). Collectively, 185 (48\%) proteins in our interaction data were identified in other studies, and 196 (52\%) proteins were postulated to be novel (Supplementary Figure 6D). All previously reported proteins that associate with AMPK are summarized in Supplementary Table S7. Considering all comparison analyses, our dataset contains a substantial amount of new information on AMPK-specific interaction. 
A $\quad$ AMPK- $\alpha 1$

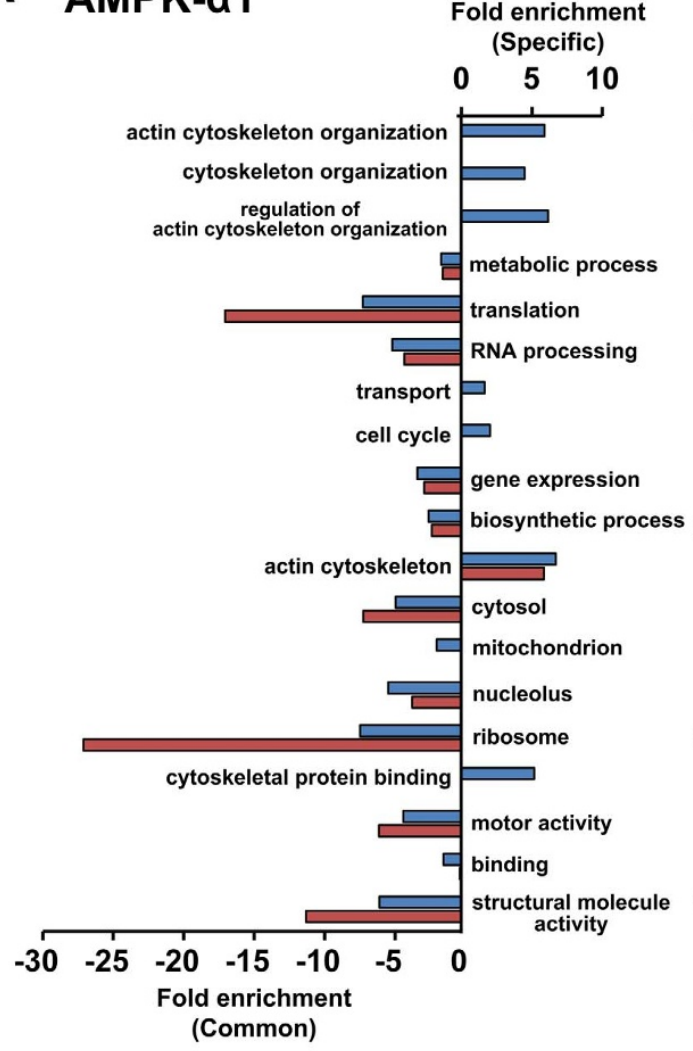

B $\quad$ AMPK- $\beta 1$





$\square$ INS-1 specific group $\square$ Human species group

Figure $4 \mid$ Functional GO annotation of AMPK- $\alpha 1$ and AMPK- $\beta 1$ interactome. All identified proteins-325 AMPK- $\alpha 1-$ and 243 AMPK- $\beta 1$-interacting proteins-were grouped, based on GO terms. GO terms enriched from proteins identified in INS-1 specific group were classified as specific, whereas those from proteins in the INS-1-specific and Human species groups were classified as common. Fold-enrichment for a particular GO term describes the ratio between the numbers of genes belonging to a specific GO term and the total number of genes in the genome with at least $1 \mathrm{GO}$ annotation. Enriched GO terms for biological process (GOBP), cellular component (GOCC), and molecular function (GOMF) are shown. In AMPK- $\alpha 1$ (A) and AMPK- $\beta 1$ (B), GO terms associated with the regulation of actin cytoskeletal organization were significantly enriched.

Because our baits are the catalytic and regulatory subunits of the AMPK complex, we expected some of its partners to be substrates for it. Thus, we determined whether the identified proteins were phosphorylated in tissues or cells and if their phosphorylation was AMPK-dependent. Our primary sources for this step were large phosphoproteome repositories, based on mass spectrometry, including the PhosphoSitePlus database ${ }^{46}$, PHOSIDA database ${ }^{47}$, and several phosphoproteomic studies in human, mouse, and $\mathrm{rat}^{48-53}$. Moreover, we predicted AMPK-dependent phosphorylation sites using GPS2. $1^{54}$ to examine the connections between the identified binding partners and AMPK.

As shown in Supplementary Figure 7A and Supplementary Table S7, more than $92 \%$ of identified proteins were phosphorylated, over $78 \%$ of which (299 proteins) were predicted to be AMPK-dependently

Table $2 \mid$ Novel interactors of AMPK associated with regulation of actin cytoskeleton

\begin{tabular}{|c|c|c|c|c|c|}
\hline Gene Symbol & Protein Name & Molecular Weight & Species & baits & Novel \\
\hline lqgapl & IQ motif containing GTPase activating protein 1 & 189 kDa & Rattus norvegicus & $\alpha 1 / \beta 1$ & O \\
\hline Arpc4 & actin related protein $2 / 3$ complex, subunit 4 & $20 \mathrm{kDa}$ & Rattus norvegicus & $\alpha 1$ & $\mathrm{O}$ \\
\hline Actg 1 & actin, gamma 1 & $42 \mathrm{kDa}$ & Rattus norvegicus & $\alpha 1 / \beta 1$ & O \\
\hline Actn 1 & actinin alpha 1 & 103 kDa & Rattus norvegicus & $\alpha 1 / \beta 1$ & $\mathrm{O}$ \\
\hline $\mathrm{Cfl} 1$ & cofilin 1, non-muscle & 19 kDa & Rattus norvegicus & $\alpha 1$ & $\mathrm{O}$ \\
\hline $\mathrm{Cfl} 2$ & cofilin 2, muscle & 19 kDa & Rattus norvegicus & $\beta 1$ & $\mathrm{O}$ \\
\hline Myhl 14 & myosin, heavy chain 14 & $232 \mathrm{kDa}$ & Rattus norvegicus & $\beta 1$ & $x$ \\
\hline Myh9 & myosin, heavy chain 9 , non-muscle & $226 \mathrm{kDa}$ & Rattus norvegicus & $\alpha 1 / \beta 1$ & O \\
\hline Ppplca & protein phosphatase 1, catalytic subunit, alpha isoform & 38 kDa & Rattus norvegicus & $\alpha 1 / \beta 1$ & O \\
\hline Ppplcb & protein phosphatase 1, catalytic subunit, beta isoform & $37 \mathrm{kDa}$ & Rattus norvegicus & $\beta 1$ & O \\
\hline Rhoa & ras homolog gene family, member $A$ & $22 \mathrm{kDa}$ & Rattus norvegicus & $\alpha 1$ & $\mathrm{O}$ \\
\hline Racl & ras-related $\mathrm{C} 3$ botulinum toxin substrate 1 & $21 \mathrm{kDa}$ & Rattus norvegicus & $\alpha 1 / \beta 1$ & O \\
\hline
\end{tabular}




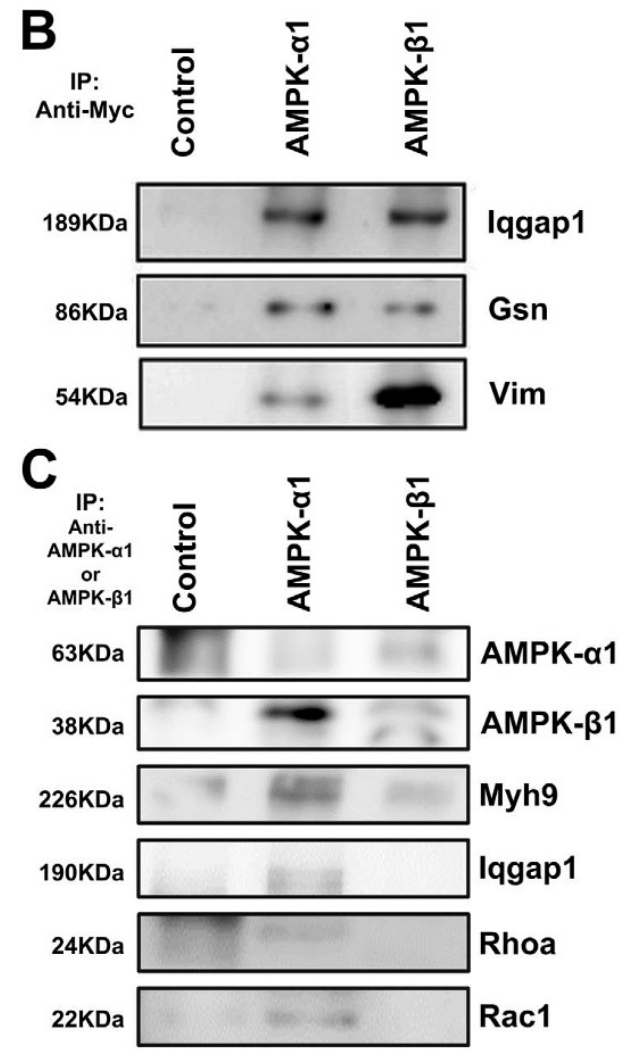

Figure 5 | Interaction network for proteins associated with AMPK complex in regulation of actin cytoskeleton. (A) Network analysis of AMPK interactome, showing that the AMPK complex interacts directly with multiple proteins associated with the regulation of the actin cytoskeleton. Proteins and protein-protein interactions associated with regulation of the actin cytoskeleton were extracted from the KEGG pathway and STRING 9.1 databases. All input proteins associated with actin regulation are depicted as small gray spheres. Interacting proteins in our dataset are depicted as green spheres, and interacting proteins validated by Co-IP are shown as yellow spheres. Bait proteins are shown as red hexagons. Protein-protein interactions extracted from the STRING database are shown as grey lines. Interactions identified in this study are shown as green lines. Co-IP-validated interactions are shown as red dotted lines. (B) Validation of protein-protein interactions by pulldown approach. A novel interacting protein (Iqgap1) was validated by co-IP. Wellknown proteins (Gsn and Vim) were also validated. Vim was used as a positive control to confirm homologous interactions. (C) Validation of proteinprotein interactions using direct IP. AMPK- $\alpha 1$, AMPK- $\beta 1$, Myh9, Iqgap1, Rhoa, and Racl were validated by co-IP. The co-IP results for novel interactors (Myh9, Iqgap1, Rhoa, and Rac1) that were associated with regulation of the actin cytoskeleton corresponded well with the AP-MS results.

phosphorylated, using GPS2.1 with moderate confidence (Supplementary Figure 7B). Further, of 1410 phosphorylation sites in the 299 proteins, 454 sites in 169 proteins were identified in earlier MSbased phosphoproteome studies (Supplementary Figure 7C and Supplementary Table S8). Detailed information on the prediction analysis using GPS2.1 is shown in Supplementary Figure 7D. For AMPK $-\alpha 1$ and $-\beta 1$, nearly $80 \%$ of interactors were predicted to have phosphorylation sites with medium confidence (Supplementary Figure 7D).

Considering proteins that have been reported to associate with or be linked functionally to AMPK, our comparison analysis suggests that $92 \%(349 / 381)$ of identified proteins are related to AMPK, corroborating the functional correlation of these proteins with AMPK and validating the reliability of our approach for discovering novel AMPK interaction partners.

We screened the AMPK- $\alpha 1$ and $-\beta 1$ interactomes through functional grouping, based on their affiliation, and sorted AMPK interactors that were derived from pancreatic beta-cells. Most AMPK- $\alpha 1$ - and - $\beta 1$-binding proteins in the INS-1-specific group regulated actin cytoskeletal organization. Because a principal function of pancreatic beta-cells is to secrete hormones on stimulation, such as insulin through actin cytoskeleton remodeling ${ }^{55,56}$, the proteins that are associated with the stimulus could be upregulated or activated in beta-cells versus other cell types, which might explain the $\mathrm{GO}$ analysis results.
Our bioinformatics analysis and literature search revealed that 16 proteins are linked to the regulation of actin cytoskeletal organization (Table 2)-Myh9, Myh10, Myh14, and Myl12b are associated with myosin class II (myosin II) activation and, as actin-binding proteins, are thus central in cell adhesion, migration, and division ${ }^{57}$. Myh9, Myh10, and Myh14 are 3 members of nonmuscle myosin II (NMII), including NMIIA, NMIIB, and NMIIC. Whereas Myh10 and Myh14 form complexes with AMPK in human cells ${ }^{41,58}$, our AP-MS and co-IP data constitute novel findings of a link between AMPK and Myh9. Recent studies have suggested that NMII modulates GSIS through actin and focal adhesion remodeling in pancreatic beta-cells ${ }^{59}$. Further, AMPK regulates cell morphology and secretion by phosphorylating Myhl12b (known as MRLC) ${ }^{19,60}$. Although AMPK controls myosin II directly ${ }^{61,62}$ and indirectly ${ }^{19,63}$ in pancreatic beta-cells, role of AMPK in regulation of myosin remain unresolved. Our data support a model in which AMPK mediates myosin II-associated beta-cell functions, including the regulation of GSIS.

Notably, several proteins (IQGAP1, gelsolin, cofilin, Rac1, and RhoA) are related to reorganization and remodeling of filamentous actin (F-actin $)^{56}$, which regulates insulin secretion in beta-cells ${ }^{56}$. As scaffolding proteins and F-actin-binding protiens, IQGAP1 and gelsolin regulate cytoskeletal reorganization ${ }^{64}$ and are also linked to pancreatic beta-cell functions, such as insulin secretion ${ }^{55,65,66}$, betacell development ${ }^{67,68}$, and cell-cell communication ${ }^{66,69}$. Whereas gel- 
solin interacts with AMPK- $\beta$ in human cells ${ }^{21}$, we report a novel interaction between AMPK and IQGAP1. Both proteins were confirmed to interact with AMPK- $\alpha 1$ and $-\beta 1$ by co-IP and western blot (Figure 5B).

Cofilin-1 and Cofilin-2 are associated with glucose homeostasis, regulating insulin-stimulated GLUT4 translocation in muscle cells ${ }^{70}$ and pancreatic beta-cells ${ }^{71}$. Rac1 is a member of the Rho family of GTPases, which govern cytoskeletal organization ${ }^{72}$. Recent evidence also implicates an association between AMPK and Rac1 in insulin secretion by pancreatic beta-cells ${ }^{56,72}$. RhoA is a small GTPase that regulates the actin cytoskeleton during the formation of stress fibers and is phosphorylated by $\mathrm{AMPK}^{73}$. Interestingly, RhoA controls several beta cell functions including beta-cell spreading and actin cytoskeleton dynamics through the Rho-ROCK pathway ${ }^{74}$.

Because most of the direct interactions between AMPK and regulators of actin reorganization have not been reported in pancreatic beta-cells, our interactome is a resource that can be used to examine novel functions AMPK in regulating actin remodeling in pancreatic beta-cells. Further, the validation of 5 proteins (Gsn, Iqgap1, Myh9, Rhoa, and Rac1) should help us determine the function of AMPKactin cytoskeleton assembly in regulating GSIS.

In conclusion, we have identified many putative partners of AMPK- $\alpha 1$ and $-\beta 1$ by combining affinity chromatography and mass spectrometry. With our stringent filtering criteria, our interactome comprised 325 and 243 proteins that interacted with AMPK- $\alpha 1$ and $\beta 1$, respectively. Our study confirms 185 previously described proteins and identified 196 novel proteins that bind AMPK in our AMPK interactome datasets. Our data reinforce a model in which AMPK governs many functions that are linked to the regulation of actin organization. Specifically, several such proteins are closely associated with pancreatic beta-cell functions, including GSIS, beta-cell development, beta-cell differentiation, and cell-cell communication. Consequently, our interactome can be used to perform more detailed biochemical analyses of putative substrates and effectors of AMPK.

\section{Methods}

Reagents and materials. HPLC-grade acetonitrile (ACN), HPLC-grade water, HPLC-grade methanol $(\mathrm{MeOH})$, hydrochloric acid $(\mathrm{HCl})$, and sodium chloride $(\mathrm{NaCl})$ were obtained from DUKSAN (Kyungkido, Korea). Acetic acid was purchased from TEDIA (Fairfield, OH, USA). Brilliant Blue G-250 and a Bio-Rad protein assay kit were purchased from Bio-Rad (Hercules, CA, USA), and Complete Protease inhibitor cocktail was purchased from Roche (Mannheim, Germany). Other reagents, including 2 -mercaptoethanol ( $\beta$-ME), ammonium bicarbonate (ABC), ammonium persulfate (APS), EDTA, iodoacetamide (IAA), magnesium chloride, MES hydrate, potassium chloride, sodium bisulfite, sodium deoxycholate (SDC), sodium pyrophosphate, and trifluoroacetic acid (TFA) were purchased from SigmaAldrich (St. Louis, MO, USA).

Cell culture. The INS-1 rat insulinoma cell line was grown in RPMI 1640 medium, containing $10 \%$ heat-inactivated fetal bovine serum, 100 units $/ \mathrm{ml}$ antibiotics, $1 \mathrm{mM}$ sodium pyruvate, $10 \mathrm{mM}$ HEPES ( $\mathrm{pH} 7.4$ ), and $50 \mu \mathrm{M} \beta$-ME, at $37^{\circ} \mathrm{C}$ in a $5 \% \mathrm{CO}_{2}$ incubator.

HEK293T cells were maintained in Dulbecco's modified Eagle's medium (DMEM) with $10 \%$ heat-inactivated fetal bovine serum and antibiotics ( $100 \mathrm{units} / \mathrm{ml}$ penicillin and $100 \mathrm{mg} / \mathrm{ml}$ streptomycin).

Plasmid construction and transient transfection. The full-length coding regions of rattus AMPK- $\alpha 1$ and AMPK- $\beta 1$ were generated by PCR of first-stand cDNA from total RNA of INS- 1 cells. Each construct was cloned into the eukaryotic pcDNA3.1-6myc-tagged expression vector (Supplementary Figure 1A). Information for constructs and primers is shown in Supplementary Figure 1B. Cloned plasmids were confirmed by sequencing. Plasmids were prepared using the Plasmid Midi kit per the manufacturer's protocol.

The plasmids were transfected into HEK293T cells by PEI method ${ }^{23,24}$. Prior to transfection, $12 \mu \mathrm{g}$ of plasmid in $2 \mathrm{ml}$ serum-free media were mixed with $36 \mu \mathrm{l}$ PEI solution $(1 \mu \mathrm{g} / \mu \mathrm{l})$ and incubated for $15 \mathrm{~min}$ at room temperature. The solution was added to $1 \times 10^{7} \mathrm{HEK} 293 \mathrm{~T}$ cells in a $150-\mathrm{cm}^{2}$ dish. Cells were incubated for 4 hours at $37^{\circ} \mathrm{C}$ in a $\mathrm{CO}_{2}$ incubator. After being washed with $10 \mathrm{ml}$ of serum-free media twice to remove excess PEI, the cells were incubated with $20 \mathrm{ml}$ of serum-containing media overnight at $37^{\circ} \mathrm{C}$. Transiently transfected cells were washed 3 times with ice-cold PBS and pelleted. The pellets were snap-frozen in liquid nitrogen and stored at $-80^{\circ} \mathrm{C}$ until further analysis.
Preparation of cell lysates. HEK293T and INS-1 cells were lysed in $200 \mu \mathrm{l}$ modified RIPA buffer, comprising $150 \mathrm{mM} \mathrm{NaCl}, 50 \mathrm{mM}$ Tris-Cl pH 7.4, 1 mM EDTA, $1 \mathrm{X}$ protease inhibitor cocktail, $0.1 \mathrm{mM}$ PMSF, $0.1 \%$ SDC, and $1 \%$ NP-40. Cells were disrupted by sonication and centrifuged at $15,000 \mathrm{rpm}$ for $40 \mathrm{~min}$ at $4{ }^{\circ} \mathrm{C}$ to remove cell debris. Protein concentration was measured by BCA assay. Anti-myc western blot analysis was used to monitor recombinant myc-AMPK expression.

Pulldown assay using anti-myc coupled to magnetic beads. Prior to immunopurification, $1 \mathrm{mg}$ each of HEK293T and INS-1 cell lysate was precleared using protein G Dynabeads at $200: 1$ (cell lysate to beads) for $4 \mathrm{hr}$ at $4^{\circ} \mathrm{C}$ on a rotary device. First, $50 \mu \mathrm{l}$ of protein G Dynabeads was washed with PBS and incubated for $1 \mathrm{~h}$ with $5 \mu \mathrm{g}$ anti-myc at room temperature. After washes with PBS, the recombinant 6-myc-tagged AMPK subunits were immobilized from precleared HEK293T cell lysates onto anti-myc-conjugated Dynabeads at $4^{\circ} \mathrm{C}$ for $4 \mathrm{~h}$.

For the pulldown, the beads were washed 3 times with $500 \mu \mathrm{l}$ RIPA buffer and mixed with precleared INS-1 cell lysate overnight at $4^{\circ} \mathrm{C}$. After nonspecific proteins were washed away, the immunopurified mixtures were incubated with elution buffer (0.1 M citrate $\mathrm{pH} 2.5)$ at room temperature for $5 \mathrm{~min}$. In the control experiment, the same immunopurification was performed using lysates from mock-transfected HEK293T cells in the immobilization step.

SDS-PAGE separation, in-gel digestion, and desalting. Immunopurified fractions of each IP were resolved in SDS sample buffer and denatured at $95^{\circ} \mathrm{C}$ for $5 \mathrm{~min}$. After protein separation by $10 \%$ Bis-Tris SDS-PAGE and staining with Brilliant Blue G250, each lane of the gel was excised, cut into 6 slices, and incubated with $500 \mu \mathrm{l}$ $200 \mathrm{mM} \mathrm{ABC}$ and $50 \% \mathrm{ACN}$ for destaining. The gel slices were then dehydrated and rehydrated with $200 \mu \mathrm{l} 100 \% \mathrm{ACN}$ and $200 \mu \mathrm{l}$ of $0.1 \mathrm{M} \mathrm{ABC}$, respectively. Disulfide bonds were reduced with $200 \mu \mathrm{l} 10 \mathrm{mM}$ DTT. Then, the proteins were alkylated with $50 \mathrm{mM}$ IAA for $30 \mathrm{~min}$ at RT in the dark.

The gel pieces were dried in a speed vacuum and incubated overnight at $37^{\circ} \mathrm{C}$ with sequencing-grade modified trypsin (Promega, Fitchburg, WI, USA) at an enzyme-toprotein ratio of $1: 100(\mathrm{w} / \mathrm{w})$. The resulting peptides were extracted sequentially from the gel slices with $100 \mu \mathrm{l} 40 \%$ ACN/50 mM ABC and $100 \mu \mathrm{l} 80 \%$ ACN/0.1\% TFA by sonication for $15 \mathrm{~min}$ at each stage. After all supernatants were combined, the peptides were dried in a speed vacuum.

The dried peptide mixtures were dissolved in $100 \mu \mathrm{l} 0.1 \%$ TFA and desalted using homemade $\mathrm{C}_{18}$-StageTips as described ${ }^{26,27}$. Briefly, $\mathrm{C}_{18}$-StageTips were prepared by packing POROS 20 R2 material (Applied Biosystems, Foster City, CA, USA) into 200$\mu$ yellow tips on top of $\mathrm{C}_{18}$ Empore disk membranes. The $\mathrm{C}_{18}$-StageTips were washed with $100 \mu \mathrm{l} 100 \% \mathrm{ACN}$ and equilibrated 3 times with $100 \mu \mathrm{l} 0.1 \%$ TFA using a syringe. After the samples were loaded, the $\mathrm{C}_{18}$-StageTips were washed 3 times with $0.1 \%$ TFA and eluted with $100 \mu \mathrm{l}$ of a gradient of elution buffers, containing $0.1 \%$ TFA and $40 \%, 60 \%$, or $80 \%$ ACN. All eluates were combined, dried on a speed vacuum, and stored at $-80^{\circ} \mathrm{C}$ until further analysis.

Direct immunoprecipitation (IP). To identify interactors of AMPK- $\alpha 1$ and AMPK$\beta 1$, we performed direct immunoprecipitation assay using INS-1 cell lysate. After protein G Dynabeads were coated with rabbit monoclonal AMPK- $\alpha$ l or AMPK- $\beta 1$ antibody as bait or normal rabbit IgG as negative control, the beads were mixed with $10 \mathrm{mg}$ of precleared INS-1 cell lysate. The immunopurified mixtures were eluted with $0.1 \mathrm{M}$ citrate buffer. One-third of the volumes of the eluate was digested by FASP as described ${ }^{27}$. The resulting peptides were desalted as described above. The remaining 2 volumes were separated by 1 -D electrophoresis on $8-15 \%$ SDS-PAGE gels and immunoblotted with antibodies of novel interacting partners for validation.

LC-MS/MS analysis. Peptide mixtures were analyzed on an EASY nano LC (Proxeon, Odense, Denmark), interfaced with an LTQ Velos mass spectrometer (Thermo Electron Corporation, San Jose, CA, USA), as described ${ }^{27}$ with some modifications. nano LC was operated in the 2 -column system with a trap column $(75 \mu \mathrm{m}$ I.D. $\times$ $4 \mathrm{~cm})$ and analytical column $(75 \mu \mathrm{m}$ I.D. $\times 15 \mathrm{~cm})$ that were packed in-house with $\mathrm{C}_{18}$ resin (Magic $\mathrm{C}_{18}-\mathrm{AQ}, 5 \mu \mathrm{m}, 100 \AA$ ). Solvent $\mathrm{A}$ was $0.1 \%$ formic acid and $2 \%$ ACN, and solvent B was $0.1 \%$ formic acid and $98 \%$ ACN. Fifty milliliters of each sample, dissolved in $50 \mu \mathrm{l}$ solvent $\mathrm{A}$, was injected into the trap column at $5 \mu \mathrm{l} / \mathrm{min}$. Peptides were eluted with a gradient of $2 \%$ to $40 \%$ solvent B over $85 \mathrm{~min}$, followed by a gradient of $40 \%$ to $90 \%$ for $15 \mathrm{~min}$ and $90 \%$ over $5 \mathrm{~min}$ at $500 \mathrm{nl} / \mathrm{min}$.

The ion spray voltage was set to $1.8 \mathrm{kV}$ in the positive ion mode, and the temperature of the heated capillary was $320^{\circ} \mathrm{C}$. A cycle of 1 precursor MS survey spectrum $(300-2000 \mathrm{~m} / \mathrm{z})$ was acquired in the profile mode. MS/MS scans were taken in the linear trap in a data-dependent manner for the 10 most abundant signal precursor MS ions. All CID MS/MS spectra were acquired using the following parameters: $35 \%$ normalized collision energy; ion selection threshold of 500 counts; activation Q of 0.25 ; and activation time of $30 \mathrm{~ms}$. Dynamic exclusion was performed with a repeat count of 1,30 -s repeat duration, exclusion list size of 50, exclusion duration of $60 \mathrm{~s}$, and $\pm 1.5 \mathrm{~m} / \mathrm{z}$ exclusion mass width. Overall, 3 technical replicates were analyzed for each dataset.

Data processing. Raw MS files were processed using the Sorcerer-SEQUEST platform ${ }^{29}$ as described with some modification ${ }^{27}$. MS/MS spectra was examined using a target-decoy database search strategy against a concatenated forward/ reversed version of the International Protein Index (IPI) rat (v 3.87, 39,925 entries) and human (v 3.87, 91,464 entries) databases, supplemented with the protein sequences of bovine serum albumin, trypsin, and 6-myc-tagged AMPK- $\alpha 1$ and 
AMPK- $\beta 1$. The database search parameters were: full enzyme digest using trypsin (After KR/-) with up to 1 missed tryptic cleavage; a parent ion mass tolerance of $2.0 \mathrm{Da}$ (average mass); a fragment ion mass tolerance of $0.8 \mathrm{Da}$ (monoisotopic mass); fixed modification of $57.02 \mathrm{Da}$ on cysteine for carboxyamidomethylation; and variable modifications of $15.99 \mathrm{Da}$ on methionine for oxidation.

The search data for each experimental scheme were merged and validated using Scaffold 4. Collected datasets were filtered, based on peptide probability, protein probability, and SEQUEST scores, to achieve an estimated false discovery rate (FDR) $<1.0 \%$. The filter criteria were as follows: for charge states of $1+, 2+$, and $3+$, Xcorr scores should be greater than $1.5,2.5$, and 3.5 , respectively; deltaCN should be larger than 0.1 ; peptide probability and protein probability should exceed 0.95 ; and the minimum number of unique peptides was set to 2 .

To identify proteins that interacted specifically with AMPK subunits and eliminate false interactions from the negative controls, significance analysis of interactome (SAINT) was performed, based on spectral counts, as described ${ }^{30,75,76}$. The probability scores of the bait and prey proteins were calculated as the average of the probabilities in individual replicates (AvgP). Proteins with AvgP $\geq 0.9$ in 1 biological replicate or that were detected in at least 2 of 4 biological replicates with $\operatorname{AvgP} \geq 0.5$ were likely interactors ${ }^{75,76}$

Bioinformatics analysis. Gene ontology was performed using DAVID Bioinformatics Resource $6.7^{31}$. Interactors were categorized into cellular compartment, molecular function, and biological process terms. Only enriched GO terms with a $p$-value $<0.05$ were selected. Pathway analysis was performed using the KEGG (Kyoto Encyclopedia of Genes and Genomes) Pathways database (http:// www.genome.jp/kegg/). A protein interaction network was generated using STRING $9.1^{39}$ and visualized with CytoScape ${ }^{40}$. AMPK-specific phosphorylation sites were predicted using GPS2. $1^{54}$. The prediction threshold values for GPS2.1 were set to high (3.081) and medium (2.324). Based on the prediction values, phosphorylation sites were classified as high confidence and medium confidence. Phosphorylation sites with low prediction values constituted the no-prediction group.

Immunoblot analysis and antibodies. Whole HEK293T and INS-1 cell lysates were prepared from $1 \times 10^{7}$ cells in $200 \mu \mathrm{l}$ RIPA buffer. Pulldown assay and direct IP assay were performed using Dynabeads as described above. Control experiments were performed using lysates from mock-transfectedHEK293T cells.

The mixtures were incubated overnight at $4{ }^{\circ} \mathrm{C}$ with rotation to capture the immune complex. The beads were pelleted by brief centrifugation and washed 3 times with RIPA buffer. Bound proteins were eluted with $100 \mu$ l elution buffer, consisting of $0.1 \mathrm{M}$ citrate. The resultant proteins were separated on an $8 \%$ to $15 \%$ SDS-PAGE gel and immunoblotted with antibodies against AMPK- $\alpha 1$ and AMPK- $\beta 1$ (Cell Signal, Boston, MA, USA), MYH9 (sc-47199), IQGAP1 (sc-10792), gelsolin (sc-48769) and RhoA (sc-179) (Santa Cruz Biotechnology, Santa Cruz, CA, USA), and Racl (05-389) (Millipore, Billerica, MA 01821, USA).

1. Hwang, J. T., Kwon, D. Y. \& Yoon, S. H. AMP-activated protein kinase: a potential target for the diseases prevention by natural occurring polyphenols. N Biotechnol 26, 17-22, doi:10.1016/j.nbt.2009.03.005 (2009).

2. Wong, A. K., Howie, J., Petrie, J. R. \& Lang, C. C. AMP-activated protein kinase pathway: a potential therapeutic target in cardiometabolic disease. Clin Sci (Lond) 116, 607-620, doi:10.1042/CS20080066 (2009).

3. Zhang, B. B., Zhou, G. \& Li, C. AMPK: an emerging drug target for diabetes and the metabolic syndrome. Cell Metab 9, 407-416, doi:10.1016/j.cmet.2009.03.012 (2009).

4. Nagata, D. \& Hirata, Y. The role of AMP-activated protein kinase in the cardiovascular system. Hypertens Res 33, 22-28, doi:10.1038/hr.2009.187 (2010).

5. Lage, R., Dieguez, C., Vidal-Puig, A. \& Lopez, M. AMPK: a metabolic gauge regulating whole-body energy homeostasis. Trends Mol Med 14, 539-549, doi:10.1016/j.molmed.2008.09.007 (2008).

6. Oakhill, J. S. et al. beta-Subunit myristoylation is the gatekeeper for initiating metabolic stress sensing by AMP-activated protein kinase (AMPK). Proc Natl Acad Sci U S A 107, 19237-19241, doi:10.1073/pnas.1009705107 (2010).

7. Hardie, D. G., Salt, I. P., Hawley, S. A. \& Davies, S. P. AMP-activated protein kinase: an ultrasensitive system for monitoring cellular energy charge. Biochem J 338(Pt 3), 717-722 (1999).

8. Hawley, S. A. et al. Calmodulin-dependent protein kinase kinase-beta is an alternative upstream kinase for AMP-activated protein kinase. Cell Metab 2, 9-19, doi:10.1016/j.cmet.2005.05.009 (2005).

9. Sanders, M. J., Grondin, P. O., Hegarty, B. D., Snowden, M. A. \& Carling, D. Investigating the mechanism for AMP activation of the AMP-activated protein kinase cascade. Biochem J 403, 139-148, doi:10.1042/BJ20061520 (2007).

10. Witters, L. A. \& Kemp, B. E. Insulin activation of acetyl-CoA carboxylase accompanied by inhibition of the 5'-AMP-activated protein kinase. J Biol Chem 267, 2864-2867 (1992).

11. Gwinn, D. M. et al. AMPK phosphorylation of raptor mediates a metabolic checkpoint. Mol Cell 30, 214-226, doi:10.1016/j.molcel.2008.03.003 (2008).

12. Koo, S. H. et al. The CREB coactivator TORC2 is a key regulator of fasting glucose metabolism. Nature 437, 1109-1111, doi:10.1038/nature03967 (2005).

13. Kahn, B. B., Alquier, T., Carling, D. \& Hardie, D. G. AMP-activated protein kinase: ancient energy gauge provides clues to modern understanding of metabolism. Cell Metab 1, 15-25, doi:10.1016/j.cmet.2004.12.003 (2005).
14. Fu, A., Eberhard, C. E. \& Screaton, R. A. Role of AMPK in pancreatic beta cell function. Mol Cell Endocrinol 366, 127-134, doi:10.1016/j.mce.2012.06.020 (2013).

15. Sun, G. et al. Ablation of AMP-activated protein kinase alpha1 and alpha2 from mouse pancreatic beta cells and RIP2.Cre neurons suppresses insulin release in vivo. Diabetologia 53, 924-936, doi:10.1007/s00125-010-1692-1 (2010).

16. Kim, W. H. et al. AICAR potentiates ROS production induced by chronic high glucose: roles of AMPK in pancreatic beta-cell apoptosis. Cell Signal 19, 791-805, doi:10.1016/j.cellsig.2006.10.004 (2007).

17. Ho, Y. et al. Systematic identification of protein complexes in Saccharomyces cerevisiae by mass spectrometry. Nature 415, 180-183, doi:10.1038/415180a (2002).

18. Gingras, A. C., Gstaiger, M., Raught, B. \& Aebersold, R. Analysis of protein complexes using mass spectrometry. Nat Rev Mol Cell Biol 8, 645-654, doi:10.1038/nrm2208 (2007).

19. Banko, M. R. et al. Chemical genetic screen for AMPKalpha2 substrates uncovers a network of proteins involved in mitosis. Mol Cell 44, 878-892, doi:10.1016/ j.molcel.2011.11.005 (2011).

20. Kocher, T. \& Superti-Furga, G. Mass spectrometry-based functional proteomics: from molecular machines to protein networks. Nat Methods 4, 807-815, doi:10.1038/nmeth1093 (2007).

21. Behrends, C., Sowa, M. E., Gygi, S. P. \& Harper, J. W. Network organization of the human autophagy system. Nature 466, 68-76, doi:10.1038/nature09204 (2010).

22. da Silva Xavier, G. et al. Role of AMP-activated protein kinase in the regulation by glucose of islet beta cell gene expression. Proc Natl Acad Sci U S A 97, 4023-4028 (2000).

23. Bertschinger, M., Schertenleib, A., Cevey, J., Hacker, D. L. \& Wurm, F. M. The kinetics of polyethylenimine-mediated transfection in suspension cultures of Chinese hamster ovary cells. Mol Biotechnol 40, 136-143, doi:10.1007/s12033008-9069-0 (2008).

24. Reed, S. E., Staley, E. M., Mayginnes, J. P., Pintel, D. J. \& Tullis, G. E. Transfection of mammalian cells using linear polyethylenimine is a simple and effective means of producing recombinant adeno-associated virus vectors. J Virol Methods 138, 85-98, doi:10.1016/j.jviromet.2006.07.024 (2006).

25. Buchse, T. et al. CIN85 interacting proteins in B cells-specific role for SHIP-1. Mol Cell Proteomics 10, M110 006239, doi:10.1074/mcp.M110.006239 (2011).

26. Rappsilber, J., Mann, M. \& Ishihama, Y. Protocol for micro-purification, enrichment, pre-fractionation and storage of peptides for proteomics using StageTips. Nat Protoc 2, 1896-1906, doi:10.1038/nprot.2007.261 (2007).

27. Han, D. et al. Comprehensive phosphoproteome analysis of INS-1 pancreatic beta-cells using various digestion strategies coupled with liquid chromatographytandem mass spectrometry. J Proteome Res 11, 2206-2223, doi:10.1021/ pr200990b (2012).

28. Wisniewski, J. R., Zougman, A., Nagaraj, N. \& Mann, M. Universal sample preparation method for proteome analysis. Nat Methods 6, 359-362, doi:10.1038/ nmeth.1322 (2009).

29. Lundgren, D. H., Martinez, H., Wright, M. E. \& Han, D. K. Protein identification using Sorcerer 2 and SEQUEST. Curr Protoc Bioinformatics Chapter 13, Unit 13 13, doi:10.1002/0471250953.bi1303s28 (2009).

30. Choi, H. et al. SAINT: probabilistic scoring of affinity purification-mass spectrometry data. Nat Methods 8, 70-73, doi:10.1038/nmeth.1541 (2011).

31. Huang da, W., Sherman, B. T. \& Lempicki, R. A. Systematic and integrative analysis of large gene lists using DAVID bioinformatics resources. Nat Protoc 4, 44-57, doi:10.1038/nprot.2008.211 (2009).

32. Green, A. S. et al. The LKB1/AMPK signaling pathway has tumor suppressor activity in acute myeloid leukemia through the repression of mTOR-dependent oncogenic mRNA translation. Blood 116, 4262-4273, doi:10.1182/blood-201002-269837 (2010)

33. Mendez, M. G., Kojima, S. \& Goldman, R. D. Vimentin induces changes in cell shape, motility, and adhesion during the epithelial to mesenchymal transition. FASEB J 24, 1838-1851, doi:10.1096/fj.09-151639 (2010)

34. Sun, G. et al. LKB1 deletion with the RIP2.Cre transgene modifies pancreatic betacell morphology and enhances insulin secretion in vivo. Am J Physiol Endocrinol Metab 298, E1261-1273, doi:10.1152/ajpendo.00100.2010 (2010)

35. Tsuboi, T., da Silva Xavier, G., Leclerc, I. \& Rutter, G. A. $5^{\prime}$-AMP-activated protein kinase controls insulin-containing secretory vesicle dynamics. J Biol Chem 278, 52042-52051, doi:10.1074/jbc.M307800200 (2003).

36. Bae, H. B. et al. AMP-activated protein kinase enhances the phagocytic ability of macrophages and neutrophils. FASEB J 25, 4358-4368, doi:10.1096/fj.11-190587 (2011).

37. Kim, E. K. et al. Activation of AMP-activated protein kinase is essential for lysophosphatidic acid-induced cell migration in ovarian cancer cells. J Biol Chem 286, 24036-24045, doi:10.1074/jbc.M110.209908 (2011).

38. Miranda, L. et al. AMP-activated protein kinase induces actin cytoskeleton reorganization in epithelial cells. Biochem Biophys Res Commun 396, 656-661, doi:10.1016/j.bbrc.2010.04.151 (2010).

39. Franceschini, A. et al. STRING v9.1: protein-protein interaction networks, with increased coverage and integration. Nucleic Acids Res 41, D808-815, doi:10.1093/ nar/gks1094 (2013)

40. Saito, R. et al. A travel guide to Cytoscape plugins. Nat Methods 9, 1069-1076, doi:10.1038/nmeth.2212 (2012). 
41. Varjosalo, M. et al. Interlaboratory reproducibility of large-scale human proteincomplex analysis by standardized AP-MS. Nat Methods, doi:10.1038/nmeth.2400 (2013).

42. Bakalarski, C. E., Haas, W., Dephoure, N. E. \& Gygi, S. P. The effects of mass accuracy, data acquisition speed, and search algorithm choice on peptide identification rates in phosphoproteomics. Anal Bioanal Chem 389, 1409-1419, doi:10.1007/s00216-007-1563-x (2007).

43. Pilot-Storck, F. et al. Interactome mapping of the phosphatidylinositol 3-kinasemammalian target of rapamycin pathway identifies deformed epidermal autoregulatory factor- 1 as a new glycogen synthase kinase- 3 interactor. $\mathrm{Mol} \mathrm{Cell}$ Proteomics 9, 1578-1593, doi:10.1074/mcp.M900568-MCP200 (2010).

44. $\mathrm{Wu}$, J. et al. Integrated network analysis platform for protein-protein interactions. Nat Methods 6, 75-77, doi:10.1038/nmeth.1282 (2009).

45. Zhang, Q. C., Petrey, D., Garzon, J. I., Deng, L. \& Honig, B. PrePPI: a structureinformed database of protein-protein interactions. Nucleic Acids Res 41, D828-833, doi:10.1093/nar/gks1231 (2013).

46. Hornbeck, P. V. et al. PhosphoSitePlus: a comprehensive resource for investigating the structure and function of experimentally determined posttranslational modifications in man and mouse. Nucleic Acids Res 40, D261-270, doi:10.1093/nar/gkr1122 (2012).

47. Gnad, F., Gunawardena, J. \& Mann, M. PHOSIDA 2011: the posttranslational modification database. Nucleic Acids Res 39, D253-260, doi:10.1093/nar/gkq1159 (2011).

48. Wisniewski, J. R., Nagaraj, N., Zougman, A., Gnad, F. \& Mann, M. Brain phosphoproteome obtained by a FASP-based method reveals plasma membrane protein topology. J Proteome Res 9, 3280-3289, doi:10.1021/pr1002214 (2010).

49. Weintz, G. et al. The phosphoproteome of toll-like receptor-activated macrophages. Mol Syst Biol 6, 371, doi:10.1038/msb.2010.29 (2010).

50. Oppermann, F. S. et al. Large-scale proteomics analysis of the human kinome. Mol Cell Proteomics 8, 1751-1764, doi:10.1074/mcp.M800588-MCP200 (2009).

51. Daub, H. et al. Kinase-selective enrichment enables quantitative phosphoproteomics of the kinome across the cell cycle. Mol Cell 31, 438-448, doi:10.1016/j.molcel.2008.07.007 (2008).

52. Olsen, J. V. et al. Global, in vivo, and site-specific phosphorylation dynamics in signaling networks. Cell 127, 635-648, doi:10.1016/j.cell.2006.09.026 (2006).

53. Olsen, J. V. et al. Quantitative phosphoproteomics reveals widespread full phosphorylation site occupancy during mitosis. Sci Signal 3, ra3, doi:10.1126/ scisignal.2000475 (2010).

54. Xue, Y. et al. GPS 2.0, a tool to predict kinase-specific phosphorylation sites in hierarchy. Mol Cell Proteomics 7, 1598-1608, doi:10.1074/mcp.M700574MCP200 (2008)

55. Tomas, A., Yermen, B., Min, L., Pessin, J. E. \& Halban, P. A. Regulation of pancreatic beta-cell insulin secretion by actin cytoskeleton remodelling: role of gelsolin and cooperation with the MAPK signalling pathway. J Cell Sci 119, 2156-2167, doi:10.1242/jcs.02942 (2006).

56. Kalwat, M. A. \& Thurmond, D. C. Signaling mechanisms of glucose-induced Factin remodeling in pancreatic islet beta cells. Exp Mol Med 45, e37, doi:10.1038/ emm.2013.73 (2013).

57. Vicente-Manzanares, M., Ma, X., Adelstein, R. S. \& Horwitz, A. R. Non-muscle myosin II takes centre stage in cell adhesion and migration. Nat Rev Mol Cell Biol 10, 778-790, doi:10.1038/nrm2786 (2009).

58. Ewing, R. M. et al. Large-scale mapping of human protein-protein interactions by mass spectrometry. Mol Syst Biol 3, 89, doi:10.1038/msb4100134 (2007).

59. Arous, C., Rondas, D. \& Halban, P. A. Non-muscle myosin IIA is involved in focal adhesion and actin remodelling controlling glucose-stimulated insulin secretion. Diabetologia 56, 792-802, doi:10.1007/s00125-012-2800-1 (2013).

60. Thaiparambil, J. T., Eggers, C. M. \& Marcus, A. I. AMPK regulates mitotic spindle orientation through phosphorylation of myosin regulatory light chain. Mol Cell Biol 32, 3203-3217, doi:10.1128/MCB.00418-12 (2012).

61. Vazquez-Martin, A., Cufi, S., Oliveras-Ferraros, C. \& Menendez, J. A. Polo-like kinase 1 directs the AMPK-mediated activation of myosin regulatory light chain at the cytokinetic cleavage furrow independently of energy balance. Cell Cycle 11, 2422-2426, doi:10.4161/cc.20438 (2012).

62. Lee, J. H. et al. Energy-dependent regulation of cell structure by AMP-activated protein kinase. Nature 447, 1017-1020, doi:10.1038/nature05828 (2007).

63. Robitaille, A. M. \& Hall, M. N. Ramping up mitosis: an AMPKalpha2-regulated signaling network promotes mitotic progression. Mol Cell 45, 8-9, doi:10.1016/ j.molcel.2011.12.018 (2012).
64. Malarkannan, S. et al. IQGAP1: a regulator of intracellular spacetime relativity. $J$ Immunol 188, 2057-2063, doi:10.4049/jimmunol.1102439 (2012).

65. Rittmeyer, E. N., Daniel, S., Hsu, S. C. \& Osman, M. A. A dual role for IQGAP1 in regulating exocytosis. J Cell Sci 121, 391-403, doi:10.1242/jcs.016881 (2008).

66. Kalwat, M. A., Wiseman, D. A., Luo, W., Wang, Z. \& Thurmond, D. C. Gelsolin associates with the $\mathrm{N}$ terminus of syntaxin 4 to regulate insulin granule exocytosis. Mol Endocrinol 26, 128-141, doi:10.1210/me.2011-1112 (2012).

67. Tekletsadik, Y. K., Sonn, R. \& Osman, M. A. A conserved role of IQGAP1 in regulating TOR complex 1. J Cell Sci 125, 2041-2052, doi:10.1242/jcs.098947 (2012).

68. Yermen, B., Tomas, A. \& Halban, P. A. Pro-survival role of gelsolin in mouse betacells. Diabetes 56, 80-87, doi:10.2337/db06-0769 (2007).

69. Hage, B., Meinel, K., Baum, I., Giehl, K. \& Menke, A. Racl activation inhibits Ecadherin-mediated adherens junctions via binding to IQGAP1 in pancreatic carcinoma cells. Cell Commun Signal 7, 23, doi:10.1186/1478-811X-7-23 (2009)

70. Chiu, T. T., Patel, N., Shaw, A. E., Bamburg, J. R. \& Klip, A. Arp2/3- and cofilincoordinated actin dynamics is required for insulin-mediated GLUT4 translocation to the surface of muscle cells. Mol Biol Cell 21, 3529-3539, doi:10.1091/mbc.E10-04-0316 (2010).

71. Wang, Z., Oh, E., Clapp, D. W., Chernoff, J. \& Thurmond, D. C. Inhibition or ablation of p21-activated kinase (PAK1) disrupts glucose homeostatic mechanisms in vivo. J Biol Chem 286, 41359-41367, doi:10.1074/ jbc.M111.291500 (2011).

72. Li, J., Luo, R., Kowluru, A. \& Li, G. Novel regulation by Racl of glucose- and forskolin-induced insulin secretion in INS-1 beta-cells. Am J Physiol Endocrinol Metab 286, E818-827, doi:10.1152/ajpendo.00307.2003 (2004).

73. Gayard, M. et al. AMPK alpha 1-induced RhoA phosphorylation mediates vasoprotective effect of estradiol. Arterioscler Thromb Vasc Biol 31, 2634-2642, doi:10.1161/ATVBAHA.111.228304 (2011)

74. Hammar, E., Tomas, A., Bosco, D. \& Halban, P. A. Role of the Rho-ROCK (Rhoassociated kinase) signaling pathway in the regulation of pancreatic beta-cell function. Endocrinology 150, 2072-2079, doi:10.1210/en.2008-1135 (2009).

75. Scifo, E. et al. Drafting the CLN3 protein interactome in SH-SY5Y human neuroblastoma cells: a label-free quantitative proteomics approach. J Proteome Res 12, 2101-2115, doi:10.1021/pr301125k (2013).

76. Skarra, D. V. et al. Label-free quantitative proteomics and SAINT analysis enable interactome mapping for the human Ser/Thr protein phosphatase 5. Proteomics 11, 1508-1516, doi:10.1002/pmic.201000770 (2011)

\section{Acknowledgments}

This work was supported by a National Research Foundation of Korea grant (No. 2011-0030740 and 2010-0029394) and the Proteogenomic Research Program, funded by the Korea government [MISP]. This work was also supported by the Industrial Strategic Technology Development Program (\#10045352), funded by the Ministry of Knowledge Economy (MKE, Korea)

\section{Author contributions}

S.M. and D.H. conceived the project, conducted all experiments including sample preparation, LC-MS/MS, data analysis, and bioinformatics analysis, and drafted the manuscript. J.J., H.M. and W.H. participated in data analysis. Youngsoo Kim directed the project and critically revised the manuscript. All authors read and approved the final manuscript.

\section{Additional information}

Supplementary information accompanies this paper at http://www.nature.com/ scientificreports

Competing financial interests: The authors declare no competing financial interests.

How to cite this article: Moon, S. et al. Interactome analysis of AMP-activated protein kinase (AMPK)- $\alpha 1$ and - $\beta 1$ in INS- 1 pancreatic beta-cells by affinity purification-mass spectrometry. Sci. Rep. 4, 4376; DOI:10.1038/srep04376 (2014).

This work is licensed under a Creative Commons AttributionNonCommercial-ShareAlike 3.0 Unported license. To view a copy of this license, visit http://creativecommons.org/licenses/by-nc-sa/3.0 